\title{
Solidified Reverse Micellar Solution (SRMS)-Based Indomethacin Sustained-Release Tablets: Formulation and In vitro Evaluation
}

\author{
Salome A Chime ${ }^{1^{*}}$, Ikechukwu V Onyishi ${ }^{1}$, Godswill C Onunkwo ${ }^{1}$ and Anthony \\ A Attama ${ }^{2}$ \\ ${ }^{1}$ Department of Pharmaceutical Technology and Industrial Pharmacy, ${ }^{2}$ Department of Pharmaceutics, University of Nigeria, \\ Nsukka 410001, Nigeria
}

*For correspondence: Email: emmymarachi@yahoo.com, salome.chime@unn.edu.ng; Tel.: +2348061329790

\begin{abstract}
Purpose: To formulate and evaluate sustained-release indomethacin tablets based on solidified reverse micellar solution (SRMS).

Methods: SRMS consisting of mixtures of phospholipid (Phospholipon ${ }^{\circledR} 90 \mathrm{H}$ ) and triglyceride (Softisan ${ }^{\circledR}$ 154) were prepared in the ratios of 1:1,2:1 and 1:2, respectively. SRMS-based tablets containing $75 \mathrm{mg}$ of indomethacin each were prepared using a validated plastic mould. The physicochemical properties of the tablet formulations were studied. In vitro release study was carried out in simulated intestinal fluid (SIF, pH 7.5).

Results: The results showed that the physicochemical properties of the tablet formulations were significantly affected by the composition/ratio of the lipid matrix used $(p<0.05)$. Tablet hardness ranged from $5.00 \pm 0.39$ to $5.60 \pm 0.36 \mathrm{kgf}$ for tablets formulated with SRMS 1:2 and 2:1 $\left(\mathrm{N}_{3}\right.$ and $\left.N_{2}\right)$, respectively. The tablets exhibited friability of $<1 \%(p<0.05)$. Erosion time in SIF ranged from $124.0 \pm$ 0.5 to $180.0 \pm 1.1 \mathrm{~min}$ while drug release from the tablets reached a maximum in $8-11 \mathrm{~h}$ for all the batches.

Conclusion: Indomethacin tablets based on SRMS exhibited good sustained-release properties and can be further developed to achieve once daily administration for improved patient adherence to therapy.
\end{abstract}

Keywords: Solidified reverse micellar solution, Phospholipid, Triglyceride, Indomethacin, Sustained release.

Tropical Journal of Pharmaceutical Research is indexed by Science Citation Index (SciSearch), Scopus, International Pharmaceutical Abstract, Chemical Abstracts, Embase, Index Copernicus, EBSCO, African Index Medicus, JournalSeek, Journal Citation Reports/Science Edition, Directory of Open Access Journals (DOAJ), African Journal Online, Bioline International, Open-J-Gate and Pharmacy Abstracts

\section{INTRODUCTION}

Indomethacin is a non-steroidal anti-inflammatory drug (NSAID) with prominent anti-inflammatory, analgesic and antipyretic properties similar to those of the salicylates. It is a more potent inhibitor of cyclooxygenase than aspirin. Oral indomethacin has excellent bioavailability; however, it has a short half-life of about $2.5 \mathrm{~h}$ and like other NSAIDs, it causes gastric irritation
[1]. Owing to the short biological half-life of this drug, a sustained action dosage form is generally preferred, to reduce frequency of administration, enhance patients' compliance, reduce its gastric irritation effect and improve its bioavailability profile.

Solidified reverse micellar solution (SRMS) consisting of phospholipid and solid lipid such as Softisan $^{\circledR} 154$, a completely hydrogenated palm 
oil, transforms into a lamellar mesophase after melting on contact with water. This transformation enables controlled release of solubilized drugs. SRMS also offer a high solubilization rate of different types of drugs [2].

Numerous polymer-based materials have been widely studied as drug carriers in the field of drug delivery [3-5]. The use of synthetic polymer matrix materials often goes along with detrimental effects on incorporated drug during manufacturing of formulations or during the degradation of the polymers after application [6]. The degradation of polymer might possibly cause systemic toxic effects through the impairment of reticulo-endothelia system (RES) or after phagocytosis of particles by human macrophages and granulocytes [7]. Therefore, alternative carrier substances have been investigated. Among them, lipidic materials have gained growing attention [8].

SRMS-based carriers have been investigated and successfully employed to achieve controlled release of drugs $[2,9,10]$. Lipid based formulations have been shown to enhance the bioavailability of drugs administered orally [1114]. The proven safety (biocompatibility) of lipid based carriers makes them attractive candidates for the formulation of pharmaceuticals. Lipid formulations generally provide increased drug solubilization for water insoluble drugs. Drug suspended in lipid matrix has been shown, in most cases to have a better absorption than conventional solid dosage forms [15]. Furthermore, bulk lipids are non adhesive and therefore, do not adhere to intestinal walls unlike most polymers and so present a good matrix for the formulation of non-steroidal anti-inflammatory drugs (NSAIDS) with high gastric irritation tendency.

This work is aimed at formulating sustained release indomethacin tablets based on SRMS for once daily administration and to evaluate the in vitro properties of the tablets, in order to improve patient's compliance.

\section{EXPERIMENTAL}

\section{Materials}

The following materials were used as procured from their suppliers without further purification: hydrochloric acid, sodium hydroxide, monobasic potassium phosphate and indomethacin (Merck, Germany), Softisan ${ }^{\circledR} 154$ (Schuppen, Condea Chemie GmbH, Germany), Phospholipon ${ }^{\circledR} 90 \mathrm{H}$ (Phospholipid GmbH, Köln, Germany), and distilled water (Lion water, Nsukka, Nigeria). Plastic mould used was constructed in the Faculty of Engineering, University of Nigeria,
Nsukka. All other reagents and solvents were of analytical grade and used as supplied.

\section{Preparation of solidified reverse micellar solutions (SRMs)}

Mixtures of Phospholipon ${ }^{\circledR} 90 \mathrm{H}$ and Softisan $^{\circledR}$ $154(1: 1,1: 2$ and $2: 1 \mathrm{w} / \mathrm{w})$, were prepared by fusion. In each case the lipids were weighed, melted together and stirred at a temperature of $70{ }^{\circ} \mathrm{C}$ using a magnetic stirrer, until a homogenous, transparent white melt was obtained. The homogenous mixture was stirred at room temperature until solidification [15-,16].

\section{Thermal analysis}

Melting transitions and changes in heat capacity of Phospholipon ${ }^{\circledR} 90 \mathrm{H}$, Softisan ${ }^{\circledR} 154$, indomethacin, SRMS $1: 1,2: 1$ and $1: 2$, were determined using differential scanning calorimeter (Netzsch DSC 204 F1, Germany). About, $10 \mathrm{mg}$ of each sample was placed in an aluminum sample pan, hermetically sealed and the thermal behaviour determined in the range $20-500{ }^{\circ} \mathrm{C}$, at a heating rate of $10 \mathrm{~K} / \mathrm{min}$ under nitrogen flux $(20 \mathrm{ml} / \mathrm{min})$.

\section{Preparation of indomethacin tablets based on SRMS}

The plastic mould used for tablet production was validated by formulating bland or unloaded tablets using the lipid matrices. With reference to the average weight of the bland tablets prepared with $1: 1,1: 2$ and $2: 1 \mathrm{w} / \mathrm{w}$ of the SRMS, the amount of indomethacin to be incorporated into each tablet was calculated. Each of the SRMS was weighed out and placed in a crucible; this was melted at $70^{\circ} \mathrm{C}$ using a magnetic stirrer/hot plate. The required amount of the active ingredient that would give $75 \mathrm{mg}$ of indomethacin per tablet was transferred into the melted lipid matrix in the crucible with stirring until a homogenous mix was obtained. The homogenous mix was scooped into the wells of the mould with a clean stainless steel spoon. It was allowed to solidify, scraped and allowed to dry at room temperature. The tablets were pressed out of the plastic mould and allowed to dry properly at room temperature.

\section{Tablet friability test}

Twenty tablets were randomly selected from each batch of the tablet. The tablets were dedusted and weighed. They were placed into the drum of the friabilator (Erweka $\mathrm{GmbH}$, Germany) and rotated 100 times at $25 \mathrm{rpm}$ for 4 $\mathrm{min}$. The tablets were removed from the 
friabilator, dedusted again and reweighed. The friability result was expressed as loss of mass expressed as a percentage of the initial mass [17].

\section{Hardness/crushing strength test}

This test was carried out using Monsanto-Stokes hardness tester (Manesty, England). Ten tablets from each batch were randomly selected. Each tablet was placed between the jaws of the hardness tester and force was applied by adjusting the knob of the tester until the tablet integrity failed. The results were recorded in kgf.

\section{Determination of erosion time of tablets}

A method described in the European Pharmacopoeia was adapted [18]. The test was carried out for each batch of the tablet using a beaker containing $500 \mathrm{ml}$ of SIF ( $\mathrm{pH}$ 7.5) maintained at $37 \pm 1{ }^{\circ} \mathrm{C}$. A thermometer was inserted into the medium to maintain the temperature. An inner compartment containing 3 tablets from each batch was tied with a thermoresistant thread unto a resort stand, and immersed into the medium. The medium was stirred at $100 \mathrm{rpm}$ with a magnetic stirrer bar. The erosion time was taken as the time taken for the tablet to change in shape and erode appreciably. This test was repeated three times for each batch and the mean erosion time was determined.

\section{Content of active ingredient}

Beer's calibration curve was obtained at a concentration range of $0.1-1.0 \mathrm{mg} \%$ for indomethacin in SIF ( $\mathrm{pH} 7.5)$ at a predetermined wavelength of $298 \mathrm{~nm}$. Twenty tablets were randomly selected from each batch of the tablets. The tablets were weighed together and crushed in a mortar with a pestle. An amount equivalent to the average weight of the crushed tablet was weighed out in an analytical balance and dispersed in distilled water. The dispersion was heated for $30 \mathrm{~min}$ at $70{ }^{\circ} \mathrm{C}$ using a magnetic stirrer/hot plate, to enhance dispersion. This dispersion was allowed to cool, filtered and an aliquot of the filtrate was assayed using a spectrophotometer (Jenway spectrophotometer, Barloworld Scientific Ltd., UK). The absorbance was recorded and the concentration of indomethacin in each tablet was calculated with reference to Beer's plot.

\section{In vitro release studies}

USP Apparatus II [17] was used in this study. The dissolution medium consisted of $900 \mathrm{ml}$ of freshly prepared SIF ( $\mathrm{pH}$ 7.5). The temperature of the medium was maintained at $37 \pm 1{ }^{\circ} \mathrm{C}$. A tablet from each batch was placed inside a tightly secured basket and the basket was placed in the bottom of the beaker. The paddle was rotated at $100 \mathrm{rpm}$. At various intervals, $5 \mathrm{ml}$-sample was withdrawn from the dissolution medium, filtered with a non adsorbent filter paper (Whatman no.1) and analysed for drug content spectrophotometrically at $298 \mathrm{~nm}$. An equal volume of the withdrawn sample was replaced with fresh medium to maintain sink condition. The amount of drug released at each time interval was determined with reference to the standard Beer's plot for indomethacin.

\section{In vitro release kinetics}

The dissolution data for the tablets were analysed to determine the in vitro release kinetic mechanism using three kinetic models including the first order equation, Higuchi square root equation and Ritger-Peppas empirical model.

$$
\begin{aligned}
& \ln Q_{t}=\ln Q_{0}-K_{1} t \\
& Q_{t}=K_{2} t^{1 / 2} \ldots \ldots \\
& M_{t} / M_{\propto}=K_{3} t^{n} \ldots .
\end{aligned}
$$

where $Q_{t}$ is the amount of drug released or dissolved at time $t, Q_{0}$ is amount of drug released or dissolved at time $\mathrm{t}=0, \mathrm{k}_{1}, \mathrm{k}_{2}$ and $\mathrm{k}_{3}$ are Firstorder, Higuchi and Ritger-Peppas release rate constant, $M_{t} / M_{\alpha}$ is the fraction of the drug released at time $t, n$ is the diffusion exponent and is an indicator of the mechanism of transport of drug through the polymer [19].

\section{Statistical analysis}

Statistical analysis was carried out using SPSS, version 14.0 (SPSS Inc Chicago, IL, USA). All data are expressed as mean $\pm S D$, and were analysed by one-way ANOVA. Differences between means were assessed by two-tailed Student's t-test. $P<0.05$ was considered statistically significant.

\section{RESULTS}

The results of thermal analysis of the materials are shown in Table 1. The results, the DSC curve of Softisan ${ }^{\circledR} 154$ showed a narrow endothermic peak, with melting peak at temperature $61.4{ }^{\circ} \mathrm{C}$. Phospholipon $^{\circledR} 90 \mathrm{H}$ showed a melting peak at temperature of $124{ }^{\circ} \mathrm{C}$. Indomethacin DSC curves showed a melting peak at $162.2{ }^{\circ} \mathrm{C}$ while those of the lipid matrices showed that the structuring of Softisan ${ }^{\circledR} 154$ with $\mathrm{P} 90 \mathrm{H}$ produced matrices with low enthalpies. 
Table 1: DSC melting peaks of materials used in formulating SRMS-based indomethacin tablets

\begin{tabular}{lc}
\hline Material & $\begin{array}{c}\text { Melting peak } \\
\left({ }^{\circ} \mathbf{C}\right)^{*}\end{array}$ \\
\hline Softisan $^{(B)} 154$ & 61.4 \\
Phospholipon $90 \mathrm{H}$ & 124.0 \\
Indomethacin & 162.2 \\
SRMS 1:1 & 65.5 \\
SRMS 1:2 & 62.3 \\
SRMS 2:1 & 65.0 \\
\hline SRMS = solidified reverse micellar solution
\end{tabular}

The results of tablet friability test, hardness, crushing strength and erosion time are presented in Table 2. All the batches of indomethacin tablets exhibited friability of less than $1 \%$ ( $p<$ 0.05), while all the batches of indomethacin tablets exhibited hardness of approximately 5 kgf. The erosion time of tablets showed that the tablet batches prepared with different ratios of lipid matrices passed the erosion time test. Indomethacin tablets formulated with lipid matrix (SRMS) 2:1 ( $\mathrm{N}_{2}$ tablets) had the highest erosion time of $180.40 \pm 1.06 \mathrm{~min}$.

The results of drug content of tablets are presented in Table 2, from the results, all the tablet batches complied with the BP standard for assay of active ingredient. All the tablets were within the range of 90 to $110 \%$ of the average value.

The release profile of indomethacin tablets studied in SIF ( $\mathrm{pH} \mathrm{7.5)} \mathrm{is} \mathrm{presented} \mathrm{in} \mathrm{Fig.} \mathrm{1.} \mathrm{The}$ results showed that indomethacin tablets formulated with the lipid matrix, SRMS 1:1 $\left(\mathrm{N}_{1}\right)$ had the fastest release of the NSAID with maximum release at $8 \mathrm{~h}$. This was followed by tablets formulated with the lipid matrix, SRMS 1:2 $\left(\mathrm{N}_{3}\right)$, which had $100 \%$ drug release at $10 \mathrm{~h}$. Tablets formulated with LM 2:1 $\left(\mathrm{N}_{2}\right)$ had the longest release rate with maximum release at 11 h. This may be due to the high softening and erosion time exhibited by this lipid matrix. Indomethacin tablets formulated with lipid matrix, SRMS 2:1 had maximum release at $11 \mathrm{~h}$, while indomethacin pure sample had maximum release at $1 \mathrm{~h}$. The results of drug release kinetics and mechanisms presented in Table 2 indicated that the Higuchi plot of amount of drug release (Q) against square root of time was linear $\left(r^{2}>0.9\right)$ for all the batches of indomethacin tablet formulations. Also plot of log $Q$ versus log $t$ gave $n$ value of $\leq 0.5$ as shown in Table 2. The first order plots, however, showed low level of linearity $\left(0.7<r^{2}<0.9\right)$. The Ritger-Peppas model for indomethacin tablets showed an $n$ value of $\leq 0.5$ for all the tablets formulations.

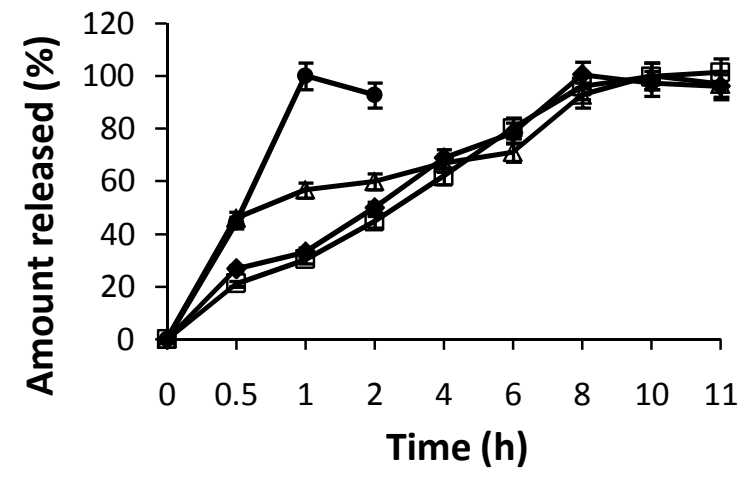

Fig 1: Release profile of three batches of indomethacin sustained release tablets; $\forall=N_{1}(1: 1)$, $\square$ $=\mathrm{N}_{2}(2: 1), \Delta=\mathrm{N}_{3}(1: 2)$, and $\bullet=\mathrm{R}_{2}$ (indomethacin pure sample)

Table 2: Some properties of SRMS based indomethacin sustained release tablets

\begin{tabular}{|c|c|c|c|c|}
\hline Batch & $\begin{array}{c}\text { Hardness } \\
(\mathrm{kgf}, \pm S D, n=10)\end{array}$ & $\begin{array}{c}\text { Friability (\%, } \\
n=20)\end{array}$ & $\begin{array}{c}\text { Erosion time } \\
(\mathrm{min}, \pm S D, n=10)\end{array}$ & $\begin{array}{c}\text { Drug content } \\
(\mathrm{mg}, \pm \mathrm{CV}, \mathrm{n}=20)\end{array}$ \\
\hline $\mathrm{N}_{1}$ & $5.10 \pm 0.24$ & 0.07 & $134.00 \pm 2.80$ & $75.27 \pm 0.39$ \\
\hline $\mathrm{N}_{2}$ & $5.60 \pm 0.36$ & 0.06 & $180.00 \pm 1.10$ & $75.12 \pm 1.10$ \\
\hline $\mathrm{N}_{3}$ & $5.00 \pm 0.39$ & 0.09 & $124.00 \pm 0.50$ & $75.20 \pm 0.75$ \\
\hline
\end{tabular}

Table 3: Release kinetics of SRMS-based sustained release indomethacin tablets

\begin{tabular}{ccccc}
\hline Batch & $\begin{array}{c}\text { Higuchi } \\
\left(\boldsymbol{r}^{2}\right)\end{array}$ & $\begin{array}{c}\text { Higuchi } \\
(\mathbf{n})\end{array}$ & $\begin{array}{c}\text { First order } \\
\left(\boldsymbol{r}^{2}\right)\end{array}$ & $\begin{array}{c}\text { Ritger-Peppas } \\
(\mathbf{n})\end{array}$ \\
\hline $\mathrm{N}_{1}$ & 0.9864 & 0.4750 & 0.7380 & 0.4780 \\
$\mathrm{~N}_{2}$ & 0.9877 & 0.5120 & 0.8212 & 0.5180 \\
$\mathrm{~N}_{3}$ & 0.9406 & 0.2530 & 0.8037 & 0.2480 \\
\hline
\end{tabular}


The DSC measurements were carried out in order to determine the melting points of indomethacin, Softisan ${ }^{\circledR}$, Phospholipon ${ }^{\circledR} 90 \mathrm{H}$, SRMS 1:1, 2:1 and 1:2. The narrow melting peak of Softisan ${ }^{\circledR} 154$ indicates the level of purity of the lipid. The thermograms of Phospholipon ${ }^{\circledR} 90 \mathrm{H}$ show that the lipid consists entirely of stable form because of the sharp melting peak seen. The sharp peak of indomethacin sample indicated the presence of pure crystalline indomethacin and the value obtained is comparable to the melting temperature recorded for indomethacin in the BP [17]. Reduction in enthalpy seen in the DSC results of the lipid matrices generally suggest less crystallinity of lipid matrices [9]. SRMS 1:1, 2:1 and 1:2 generated imperfect matrices (due to distortion of crystal arrangement of individual lipids after melting and solidification), which may have created numerous spaces for drug localization [9].

Indomethacin tablets based on SRMS were smooth and spherical with no form of depressions or cracks seen in any of the batches. The nature of drug contributed to the smooth and uniform surface seen in the tablets. Indomethacin solubilized in the lipid matrix and gave light yellow tablets. The results of tablets friability showed that the tablets can withstand handling, packaging and transportation without affecting the integrity of the products. The results of crushing strength showed that the mechanical properties of the tablet will not be compromised during long term storage. Erosion time is important because the tablet should erode appreciably in order to enhance drug release and make the drug available for absorption. Sustained release preparation and enteric coated tablets are expected to disintegrate or erode appreciably in SIF within $2 \mathrm{~h}$ [20]. However, batch $\mathrm{N}_{2}$ had erosion time of up to $180 \mathrm{~min}$; this may be due to the lipophilicity of the drug in the lipid matrix and formation of more compact matrix seen in lipid matrix, SRMS 2:1.

The results of drug content showed that the drug was not lost either by physical or chemical means uniformity of content. The release profiles of the drug show that the rate of indomethacin release from tablet formulations were not comparable to the pure sample of indomethacin used as the reference sample. The ratio of phospholipid in the lipid matrix affected the rate of drug release. Increase in phospholipid ratio prolonged the rate of drug release and this may be due to the increase in hardness, softening and erosion time seen when the ratio of phospholipid was increased above Softisan ${ }^{\circledR}$ ratio, i.e., batch $\mathrm{N}_{2}$. All the batches of indomethacin exhibited good release properties and are recommended for the formulation of sustained release preparations for once daily administration.

Higuchi release data show an $n$ value of $<0.51$ which confirms that diffusion-controlled process was predominant mechanism of drug release [21]. Ritger-Peppas model for indomethacin tablets indicate that the tablet formulations exhibited Fickian diffusion release mechanism with $n$ value of $\leq 0.5[19]$.

\section{CONCLUSION}

SRMS can be used to formulate sustained release indomethacin for once daily administration to reduce the frequency of administration of this drug, increase its bioavailability, enhance patients' compliance and reduce some side effect due to high dosing, amongst others. However, further research into this field of research is recommended for scaleup of the process.

\section{ACKNOWLEDGEMENT}

The authors wish to thank Phospholipid $\mathrm{GmbH}$, Köln, Germany for providing samples of Phospholipon ${ }^{\circledR} 90 \mathrm{H}$.

\section{REFERENCES}

1. Burke A, Symth E, and FitzGerald, GA. Analgesicantipyretic and anti-inflammatory agents; Pharmacotherapy of Gout. In: Goodman and Gilman's The Pharmacological Basis of Therapeutics, $11^{\text {th }}$ Edn. MCGraw- Hill Medical Publishing Division USA, 2006; pp 677-698.

2. Friedrich I, Müller-Goymann CC. Characterization of solidified reverse micellar solutions (SRMS) and production development of SRMS-based nanosuspension. Eur J Pharm Biopharm 2003; 56: 111-119.

3. Singh DM, Singh SS, Dixit VK, Saraf S. Formulation optimization of metronidazole loaded chitosan microspheres for wound management by 3-factor, 3level box-behnken design. Micro and Nanosystems 2010; 2: 70-77.

4. Singh DM, Singh SS, Dixit VK, Saraf S. Optimization and Characterisation of gentamicin loaded chitosan microspheres for effective wound healing $X$. Ind $J$ Pharm Educ Rev 2010; 44: 171-182.

5. Owlia PL, Sadeghzadeh F, Orang $M$, Rafienia and Bonakdar S. Evaluation of ceftriaxone releasing from microspheres based on starch against Salmonella spp. Biotech 2007; 6: 597-600.

6. Reithmeier HJ, Herrmann and Gopferich A. Development and characterisation of lipid microparticles as a drug carrier for somatostatin. Int J Pharm 2001; 218: 133143.

7. Kumar MNVR. Nano and microparticles as controlled drug delivery devices. J Pharm Pharm Sci 2000; 3: 234-258.

8. Rawat Singh $M$, Singh $D$, Saraf S. Influence of selected formulation variables on the preparation of peptide loaded lipospheres. Trend Med Res 2011: 1-15. 
9. Umeyor EC, Kenechukwu FC, Ogbonna JD, Chime SA Attama AA. Preparation of novel solid lipid microparticles loaded with gentamicin and its evaluation in vitro and in vivo. J Microencapsul 2012; 1-12. DOI: 10.3109/02652048.2011.651495.

10. Schneeweis A, Muller-Goymann CC. Controlled release of solid-reversedmicellar- solution (SRMS) suppositories containing metoclopramide- $\mathrm{HCl}$ Int $\mathrm{J}$ Pharm 2000; 196: 193-196.

11. Hou DZ, Xie CS, Huang $\mathrm{K}$, Zhu $\mathrm{CH}$. The production and characteristics of solid lipid nanoparticles (SLN). Biomaterials 2003; 24: 1781-1785.

12. Sarkar NN. Mifepristone: bioavailability, Pharmacokinetics and useful-effectiveness. Eur J Obstet Gynaecol Reprod Biol 2002; 101: 113-120.

13. Gao P, Guyton ME, Huang T, Bauer JM, Stefanski KJ, Lu Q. Enhanced oral bioavailability of a poorly water soluble drug PNU-91325 by supersaturable formulations. Drug Dev Ind Pharm 2004; 30: $221-$ 229.

14. You J, Cui F, Zi Q, Han X, Yu Y, Yang M. A novel formulation design about water insoluble oily drug: Preparation of Zedoaryl tumeric oil microspheres with self emulsifying ability and evaluation in rabbits. Int $J$ Pharm 2005; 288: 315-323.

15. Attama $A A$, Okafor $C E$, Builders PF, Okorie $O$. Formulation and invitro evaluation of a PEGylated microscopic lipospheres delivery system for ceftriaxone sodium. Drug Deliv 2009; 16: 448-616.

16. Friedrich I,Muller-Goymann CC. Characterization of solidified reverse micellar solutions (SRMS) and production development of SRMS-based nanosuspension. Eur J Pharm Biopharm 2005; 56: 111-119.

17. British Pharmacopoeia. The Commission Office London. 2009; Vol. 111: pp 6578-6585.

18. European Pharmacopoeia. Council of Europe, Strasbourg, 2005; pp 225-258.

19. Singh J, Gupta S, Kaur H. Prediction of in vitro drug release mechanisms from extended release matrix tablet using SSR/SR ${ }^{2}$ techniques. Trends App Sci Res; 2011; 6(4): 400-409.

20. Ofoefule SI. Tablet dosage forms 111. In: Ofoefule SI (ed), Textbook of Pharmaceutical Technology and Industrial Pharmacy. Samakin (Nig.) Enterprises, Lagos, Nigeria, 2002; pp 58-66.

21. Ofoefule SI, Chukwu A. Sustained release dosage forms: design and evaluation of oral products. In: Ofoefule SI (ed), Textbook of Pharmaceutical Technology and Industrial Pharmacy. Samakin (Nig.) Enterprises, Lagos, Nigeria, 2002; pp 94-120. 